\section{ENTRE OS TRILHOS, A ESTAÇÃO E AS MEMÓRIAS: O PAPEL DA ESTRADA DE FERRO PARA O DESENVOLVIMENTO DA CIDADE DE CEDRO-CE.}

\author{
Between the rails, the station and the memories: the role of the railway of \\ the development of the city of Cedro-CE.
}

\author{
Antônio Kinsley Bezerra Viana* \\ *Doutorando no curso de Pós-Graduação em Geografia da UECE/ProPGeo - Kinsley.bezerra@aluno,uece.br \\ Recebido em 28/06/2019. Aceito para publicação em 30/07/2019. \\ Versão online publicada em 10/09/2019 (http://seer.ufrgs.br/paraonde)
}

\begin{abstract}
Resumo:
As ferrovias tiveram uma grande importância no processo de expansão do capitalismo. No território cearense não ocorreu de forma diferente, as ferrovias tinham como atribuições adentrar ao interior do estado e estabelecer vários entrepostos comerciais, assegurando um fluxo constante de mercadorias, produtos agrícolas, pessoas e informação ao longo dos trilhos, interligando os mercados consumidores do litoral cearense com as principais praças comerciais e zonas produtoras do interior do Ceará e estados vizinhos. Para melhor compreender a influência da Rede Viação Cearense para a organização espacial das pequenas cidades às margens dos seus trilhos, resolvemos realizar um estudo histórico sobre a influência da ferrovia para a organização socioespacial da cidade de Cedro-CE. Nessa perspectiva analisaremos a atuação da ferrovia nos processos históricos, socioespaciais e econômicos que levaram a formação e desenvolvimento do município, e como isso ficou registrado no atual espaço urbano, influenciando o cotidiano da cidade.
\end{abstract}

Palavras-chave: Cedro. Ferrovia. Paisagem urbana. Patrimônio historico.

\begin{abstract}
:
The railway had a large importance at the process of expansion of capitalism. In the territory of Ceará did not occur in a different form, the railways had like assignments to get in to the interior of the state and establish several commercial warehouses, ensuring a steady flow merchandise, agricultural products and information over the rails, interconnecting the consumer market of Ceará coast with the principal commercial square and producing areas of the interior of Ceará and neighboring states. To better understand the influence of Rede Viação Cearense for the socio-spatial organization of the city of CedroCe. In this perspective we will analyze the railroad's performance in the historical, socio-spatial and economic processes that led to the formation and developments of the municipality, and how this was registered in the present urban space, influencing the daily life of the city.
\end{abstract}

Key-words: Cedro, railroad. Urban landscape, historical patrimony

\section{Introdução}

As ferrovias tiveram uma grande importância no processo de expansão do capitalismo. A partir do século XIX foram responsáveis por intensificar a circulação de pessoas e mercadorias, aumentando as relações comerciais e a fluidez do capital. Símbolo do progresso e do dinamismo econômico, trazia consigo novos hábitos, costumes e mercadorias, transformando significativamente o espaço ao longo dos trilhos. Para BORGES apud FICI (2010, p. 11) "As estradas de ferro além de estimular os deslocamentos da população e das mercadorias, expandiram o sistema capitalista", aumentando assim, o raio de ação das potências imperialistas para além dos limites das 
suas tradicionais zonas de atuação, estabelecendo ao redor do globo, uma extensa e complexa rede comercial que adentrava no interior dos territórios, em busca de matériasprimas e novos mercados comerciais. Consolidando assim, a influência econômica, política e cultural sobre novos territórios, além de maximizar a exploração daqueles que tradicionalmente já dominavam.

No caso brasileiro, a implantação das primeiras estradas de ferro ocorreu de modo a integrar às zonas portuárias espalhadas pelo litoral, com as regiões produtoras de matérias primas no interior do país. Com uma economia predominantemente agraria, e estruturada em polos regionais produtivos, com graves dificuldades de integração entre as zonas produtoras e as praças comerciais, devido à grande extensão do nosso território. Era necessário um sistema de transporte barato e que fosse capaz de agilizar o escoamento da produção, as relações comerciais, e o pleno transporte de pessoas e mercadorias entre as várias regiões do Brasil. Os primeiros trilhos a serem implantados no Brasil estavam associados a projetos que tinham por objetivos facilitar o escoamento das culturas de exportação, como foi o caso das ferrovias paulistas, justificadas pela atividade cafeeira.

De acordo com Borges (2011, p. 31), a implantação das estradas de ferro no Brasil foi além da simples difusão de inovações nos meios de transportes e comunicação; é na verdade, um marco na organização da produção monocultora, em particular a cultura do café, permitindo a passagem do sistema mercantil-escravista para a organização capitalista de produção. As ferrovias proporcionaram a inclusão de novos agentes produtivos e novas relações de produção, possibilitando uma modernização econômica e social para algumas regiões do país.

\section{Desenvolvimento}

No sertão nordestino essa nova realidade fez com que inúmeras vilas se desenvolvessem, outras surgissem em função das estradas de ferro, as quais transformaram consideravelmente o espaço e a história do Nordeste (PROCHNOW, 2014). No território cearense não ocorreu de forma diferente, as ferrovias tinham como atribuições, adentrar ao interior do estado e estabelecer vários entrepostos comerciais, assegurando um fluxo constante de mercadorias, produtos agrícolas, pessoas e informação ao longo dos trilhos, interligando os mercados consumidores do litoral cearense com as principais praças do interior do Ceará e dos estados vizinhos. Os primeiros projetos propondo a construção de estradas de ferro no território cearense constam da segunda metade do século XIX. Eles representam, o desejo das elites locais em transformar, através da estrada de ferro, a realidade socioeconômica da província, assolada periodicamente pelo flagelo da seca.

Conforme Assis (2011, p. 60), havia no período quatro projetos em discussão: O projeto Fortaleza - Pacatuba - Baturité - Crato; O projeto Mundaú - Itapipoca Imperatriz; O projeto Aracati - Icó - Crato; e o projeto Acaraú - Sobral - Ipu. Apenas dois desses projetos se concretizaram, o primeiro que viria a ser a Estrada de Ferro Baturité e o último que se tornaria a Estrada de Ferro Sobral. Esses projetos se tornariam as principais ferrovias da Rede Viação Cearense (Ver figura 01). O principal objetivo dessas ferrovias eram interligar os mercados consumidores do litoral cearense com importante praças comerciais e zonas produtoras do interior. Para Camelo Filho 
Entre as ferrovias de integração implantadas no Nordeste, a E.F. Baturité conseguiu ter uma composição peculiar no Brasil; ou seja, ao mesmo tempo ser de caráter nacional e de embrenhamento, uma ferrovia do café, das "secas", do algodão, do açúcar, e atender aos interesses nacional, regional e local. Transportava produtos que atendiam às necessidades dos mercados externo (café, algodão, fumo, açúcar e peles), e internos (os cereais) transportava passageiros (nos dois sentidos) e mercadorias vindas do exterior e da capital. (CAMELO FILHO, 2000, P. 96)

Inicialmente a E. F. Baturité foi construída para ligar a capital Fortaleza a região serrana de Baturité, polo produtor de café e outros gêneros agrícolas. Quando o governo imperial encampou a companhia, elaborou o processo de expansão da ferrovia com o intuito de integrar várias regiões do estado, à medida que se direcionava ao sul do Ceará estenderia sua zona de atuação ao interior das províncias da Paraíba e Pernambuco seguindo em direção as margens do rio São Francisco. Este plano de expansão não chegou a ser estruturado, os trilhos da R. V. C., jamais chegaram as margens do São Francisco. Mesmo assim, a Rede Viação Cearense chegou a estruturar uma malha ferroviária que interligava o interior do Ceará e algumas regiões do Piauí e Paraíba ao porto da capital cearense, totalizando 1.124,154 km de extensão. Mesmo não possuindo a complexidade das malhas ferroviária de outras regiões do país, a R. V. C. foi responsável por interligar uma área de centenas de quilômetros entre as províncias do Ceará, Paraíba e Piauí, possibilitando que essas regiões acessassem os litorais de Fortaleza e Camocim.

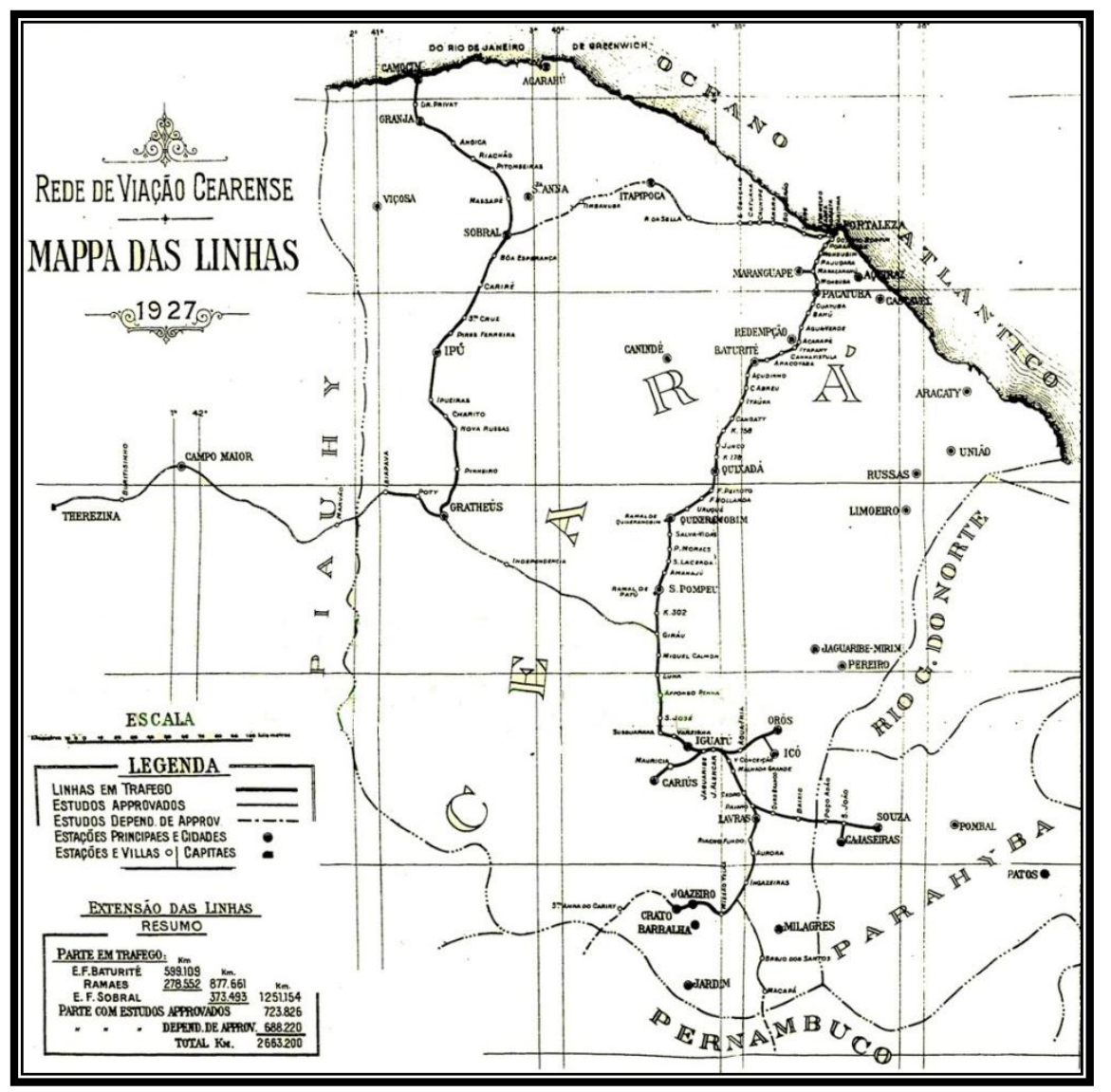

Figura 1: Mapa das linhas da Rede Viação Cearense. Ministério da Viação e Obras Públicas - 1927.

Imprensa Nacional, 1930. Apresentação: Flavio R. Cavalcanti. Fonte: http://vfco.brazilia.jor.br/ferrovias/mapas/1927-Rede-ViacaoCearense.shtml Acesso: 06/2017. 
Além de ser uma via de mão dupla entre mercadorias vindas de outras praças e matérias primas do interior, os trilhos da R. V. C. foram responsáveis por fomentar o desenvolvimento de vários núcleos urbanos ao longo dos trilhos, suas funções eram para servir de apoio logístico as atividades da ferrovia e entrepostos. Para Monastirsky

\begin{abstract}
A participação da ferrovia no processo de urbanização brasileiro está na formação de novas cidades provenientes das linhas de penetração para o interior, que surgiram em função das atividades econômicas pelas quais a ferrovia foi implantada e/ou por função logística do funcionamento da própria rede ferroviária. Também a ferrovia auxiliou na incrementação material e social de pequenas e médias cidades, que definitivamente substituíram o modelo rural ao urbanizarem-se. (MONASTIRSKY, 2006, P. 75)
\end{abstract}

Os núcleos urbanos que se desenvolviam ao longo das ferrovias, na maioria das vezes articulavam uma economia ligada diretamente ao sistema ferroviário, pois serviam de entrepostos em escala microrregional para os produtos comercializados. Além do mais, o conjunto de cidades que se desenvolveram ao longo dos trilhos, tiveram um papel de destaque na formação da rede urbana brasileira. Para Spósito

O traçado das ferrovias que interligavam pequenos e grandes centros urbanos e, em nível intermediário, as aglomerações com características rurais - que ora cresciam e se tornavam cidades, ora desapareciam com a decadência da economia microrregional são o primeiro desenho que se consolida na formatação da rede urbana brasileira. (SPÓSITO 2008, p. 62)

A cidade de Cedro, localizado na Região Centro-Sul do Ceará, situada a 468 km de Fortaleza (figura 1), foi um dos núcleos urbanos que surgiram às margens da ferrovia. $A$ partir de uma pequena propriedade rural denominada "Fazenda Cedro", encravada entre as cidades de Lavras da Mangabeira e Várzea Alegre, com a chegada dos trilhos e a construção da estação ferroviária em 1916, a fazenda dá lugar a um pequeno povoado, atraindo gradativamente um número cada vez maior de pessoas, instalavam-se pequenas vendas e oficinas, ergue-se uma igreja em homenagem a São João Batista. Diferente do que nos mostra Marx (1991), a sede religiosa não foi o ponto basilar para a fundação do povoado, como foi na maioria dos municípios brasileiros, e não determinou o fluxo de ordenamento enquanto marco urbano1. No iniciante núcleo urbano de Cedro, estes marcos foram atribuídos à estação ferroviária e à antiga casa da fazenda, como as primeiras edificações registradas na história e na memória da população.

Entre 1915 e 1918, Cedro deixou de ser uma fazenda para se tornar um próspero núcleo urbano. Com ruas que exibiam construções "ainda vermelhas, davam a impressão da azafama e da pressa reinante"2 Nesse contexto, o espaço urbano de Cedro se organizou de modo a facilitar as relações comerciais, a cidade seguiu um padrão espacial comum aos núcleos urbanos que surgiram ao longo das ferrovias, onde os armazéns, estabelecimentos comerciais e as usinas foram instaladas às margens dos trilhos e próximos a estação.

1 Murillo Marx (1991) afirmava que na maioria dos municípios brasileiros, a Igreja foi durante muito tempo, o marco para legitimar a posição do núcleo urbano na hierarquia urbana regional. Além de ser responsável por orientar o ordenamento espacial das vilas e cidades, impondo regras para construir as igrejas e o seu entorno.

2 Referência ao artigo do Jornal A Esquerda, periódico fortalezense, publicado em 30 de abril de 1928. 
A elevação à categoria de Vila e sede de Município veio a ocorrer através da Lei Estadual no 1725, de 09 de julho de 1920, garantindo a delimitação do seu território, desmembrando-a dos municípios vizinhos de Várzea Alegre, Lavras da Mangabeira, Icó e Iguatu (IBGE, 2018). E por ser sede de município, poderiam escolher seus representantes, mas estavam subordinados juridicamente à comarca de Lavras da Mangabeira, contando apenas com um tabelião. A emancipação só ocorreu cinco anos depois, através da promulgação da Lei $n^{\circ} 2255$ de 19 de agosto de 1925 . Essa condição de Vila com municipalidade, de acordo com Pontes (2010, p. 39-43), no período da República Velha, não tinha uma devida regulamentação para o processo de "divisão político-administrativa; para cada novo município, este correspondia a uma legislação individual, tendo por base as Leis Provinciais, os Decretos Leis e Resoluções"

A localização próxima aos trilhos bem como a proximidade com importantes ramais, garantia uma maior circulação de pessoas e mercadorias, gerando uma demanda constante de serviços (hotéis, restaurantes, armazéns e lojas varejistas e de atacado etc.), aumentando a oportunidades de negócios. Possibilitando ao recém-criado núcleo urbano, se tornar um relevante entreposto comercial, colaborando para a instalação de vários empreendimentos comerciais.

Essa diversidade de origens, interesses e orientações políticas e religiosas, deixaram na paisagem cedrense formas e simbologias que nos permitem perceber algumas características da sociedade que a estruturou. As formas simbólicas ainda presentes na paisagem cedrense, como as Usinas, SENAI, as Igrejas e o complexo ferroviário nos permitem compreender alguns parâmetros que existiram nas primeiras décadas da cidade. Se levarmos em conta a expressiva atividade manufatureira e a necessidade de qualificação de mão de obra, justifica o SENAI ter sido implantado ainda na década de 1950, poucos anos após a escola iniciar as atividades no Ceará, ou, se considerarmos o fato que a Igreja Presbiteriana com a sua arquitetura imponente foi edificada no final da década de 1920 pouco tempo após a emancipação e construção da Igreja Matriz, evidencia a presença dos evangélicos desde a origem da cidade, e a sua necessidade de espaço e representação em uma sociedade emergente, conservadora e predominantemente católica. Já o complexo ferroviário com as diversas estruturas, nos mostram a complexidade da atividade e a sua importância. Esses e outros eventos que ficaram registrados na memória coletiva, e que são evidenciados cotidianamente na paisagem de Cedro, ajudam a estabelecer um elo entre a história local e as pessoas que a habitam.

Além disso, a região apresentava um elevado potencial agrícola, e uma facilidade de escoar a produção, a cotonicultura3 tornou-se um dos principais pilares econômicos do lugar, estruturando uma cadeia produtiva que atuava da produção ao beneficiamento. A paisagem ao longo dos trilhos sofreu ao longo desse processo enormes transformações, a difusão de técnicas modernas alterava os processos produtivos, substituía o tempo cíclico e lento das estações do ano, pelo tilintar das máquinas e o tique-taque frenético do relógio. O Cedro surgiu sobre essas circunstâncias, e dessa forma, em apenas de dez anos a pequena fazenda se tornou uma próspera cidade às margens dos trilhos, tornando-se um respeitado mercado para a produção e comércio do algodão, além dos gêneros que circulavam pela ferrovia.

Aos poucos, empreendimentos públicos e privados foram se instalando no pequeno núcleo urbano, fortalecendo algumas atividades econômicas que se tornaram essenciais

3 Cotonicultura - cultivo do algodão. Durante décadas o Ceará foi um dos principais produtores de algodão do Nordeste, sendo a cidade do Cedro um dos polos produtores cearenses. 
para o novo município. Vale destacar as atividades do complexo ferroviário pertencente a Rede Viação Cearense como, a estação ferroviária e a oficina regional, além de proporcionar um fluxo diário de passageiros, atraíam um contingente de trabalhadores que vinham para o pequeno núcleo urbano, com o intuito de trabalhar nos equipamentos da R. V. C. Nos textos de Jucá, é possível perceber a importância da oficina para o município

Quanto a Cedro, a situação desfrutada decorria de uma configuração mais peculiar: a sua localização geográfica, na região centro sul do Ceará, onde havia a bifurcação da ferrovia. Um ramal se dirigia ao interior paraibano, pois chegava até a cidade de Sousa e o outro dava continuidade ao roteiro que ligava Fortaleza à rede urbana do sul do Estado, na região do Cariri. A instalação das oficinas de manutenção e reparo das máquinas e vagões atraiu um número considerável de funcionários e pessoas envolvidas com o transporte ferroviário, fortalecendo o papel desfrutado pela cidade no cenário interiorano. (JUCÁ, 2003, p. 40)

A cidade teve por décadas um dinamismo socioeconômico que marcou a paisagem, e principalmente, a história e a memória das pessoas que viveram esse período. $\mathrm{O}$ relógio da estação e os apitos das usinas de algodão marcaram durante décadas o ritmo e o cotidiano da cidade. A estação ferroviária representa para a maioria dos habitantes, o símbolo de um período de progresso para a cidade, no qual, as pessoas que viveram esse momento, atribuem um enorme valor emocional, histórico e cultural, maiores que os valores concretos atribuídos a estrutura física da edificação, quer seja elas econômicos, imobiliários etc. Esses valores, de algum modo, são repassados para as novas gerações que os transformam em laços identitários, tanto com a paisagem urbana, quanto com a história da cidade.

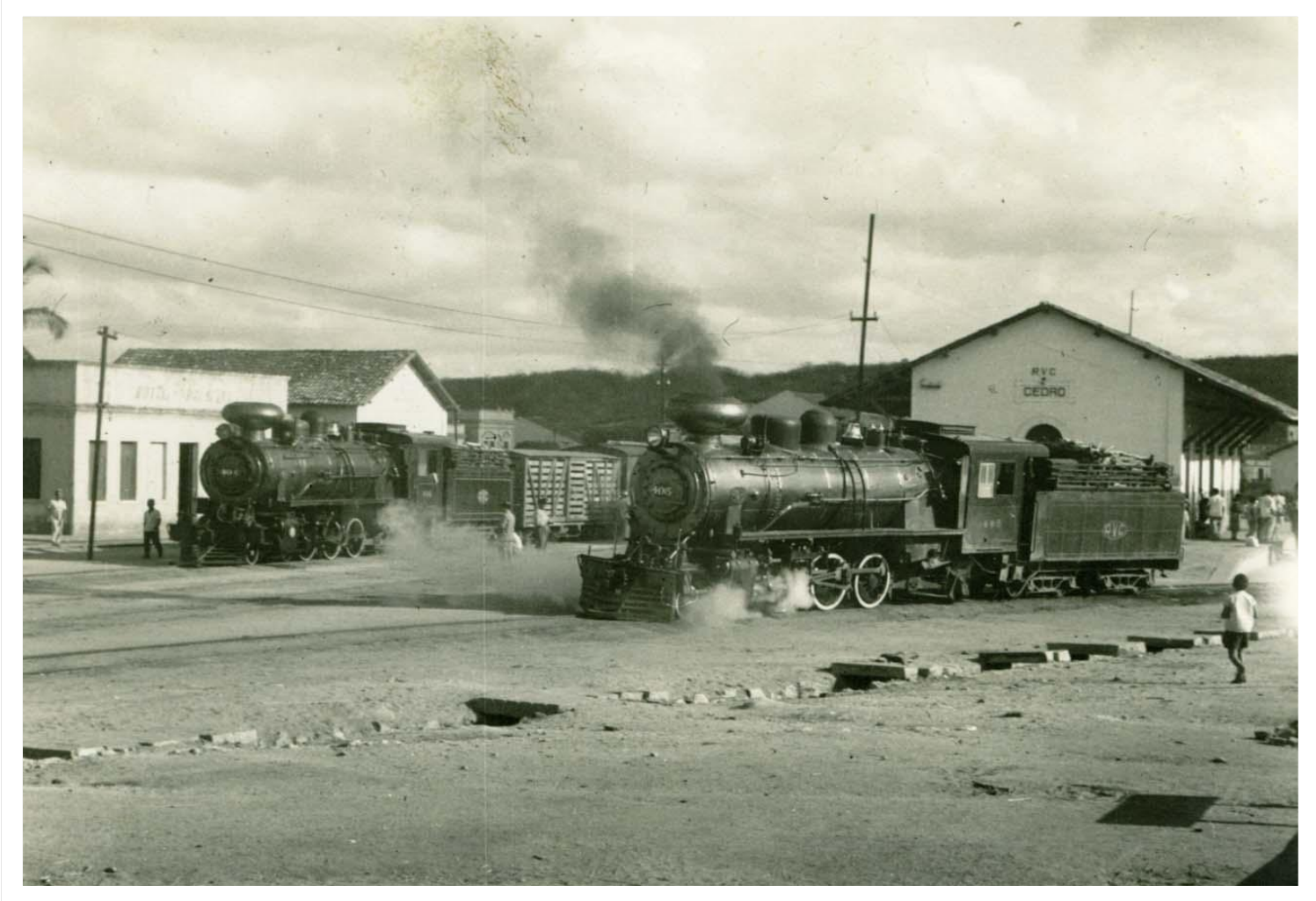

Figura 2: Estação de Cedro em 1957. Fonte: IBGE 
Apesar do declínio da atividade algodoeira e o fim do transporte ferroviário no Ceará, a paisagem urbana da cidade de Cedro conta com um número significativo de edificações que ao longo dos anos, a população aprendeu a atribuir valores e significados, e mesmo com o passar dos anos e a refuncionalização dos prédios, os símbolos permaneceram gravados na memória da população. A exemplo desse processo são as festividades realizadas no dia dos ferroviários. De acordo com Pereira e Muniz (2011, p. 62)

\begin{abstract}
O cedro ficou sem o trem, na prática, mas não o deixou fora do seu cotidiano. Todos os anos, várias caravanas de ex-funcionarios cearenses, aposentados, se deslocam à cidade para participar das comemorações. A partir de 2003, por três vezes conseguiram pôr em operação uma litorina para ir de Iguatu-Cedro, trecho de aproximadamente $30 \mathrm{~km}$. Em 2005 o vagão foi ocupado por 70 adolescentes, escolhidos entre os melhores alunos das escolas públicas da cidade. Viajaram do Cedro à estação de Arrojado, trecho com menos de $20 \mathrm{~km}$. Na hora do embarque, um homem idoso, sego, suplicou para embarcar, pois guardava na memória e no corpo as sensações que $O$ andar de trem Ihe transmitira outrora. Dois dos estudantes the cederam $o$ assento que partilhariam. A experiência foi repetida em anos seguintes, até 2007, porém sem o embarque de pessoas, porque a ANTT já não permitia o tráfego de trens de passageiros. Nos últimos anos, quatro carros foram deslocados de Fortaleza para Iguatu e simbolicamente percorreram o trecho Várzea-Cedro $(12 \mathrm{~km})$. Os carros circularam, vazios, e, ao chegarem na estação do Cedro, foram recebidos por uma multidão e por um ex-ferroviário que, paramentado à antiga, com traje e quepe de chefe da estação, batia o sino avisando que o trem lá vinha. Nos últimos anos, o evento se repete, mas sem o trem a circular.
\end{abstract}

Um papel de destaque é atribuído a estação ferroviária, além da sua importância histórica, sua localização na área central da cidade, ao lado da praça da matriz e da área comercial, é um elemento que está constantemente presente no campo visual de qualquer pessoa no centro comercial ou que esteja se deslocando de um ponto a outro da cidade. É, portanto, um ponto de passagem, uma forma simbólica espacial, para aqueles que vivem cotidianamente a cidade. Desse modo, a estação ferroviária é fortemente marcada por uma carga simbólica, fazendo com que ela seja um elemento presente no imaginário popular, reproduzindo os significados edificados pela sociedade.

Para compreendermos a permanência ativa dos símbolos na memória dos habitantes de Cedro, devemos compreender as palavras de Ecléa Bosi $(2003$, p. 71) quando ela afirma: "as lembranças se apoiam nas pedras da cidade. Se o espaço, para Merleau-Ponty, é capaz de exprimir a condição de ser no mundo, a memória escolhe lugares privilegiados de onde retira sua seiva." Portanto, locais como a antiga sede da fazenda Cedro, a estação ferroviária, a Igreja Matriz, a Igreja Presbiteriana, a Vila dos Operários, o Correio Velho, os prédios das usinas de algodão, o prédio do SENAI, e tantos outros que permeiam a paisagem local, são exemplos de formas e lugares que pela importância simbólica e afetiva permaneceram no imaginário da população cedrense, reestabelecendo ao longo dos anos vínculos identitários entre o povo e o espaço que estes habitam. Segundo Costa (2003, p. 38), "a paisagem reveste-se de elementos nostálgicos que invadem sua essência e permitem se contaminar por outras memórias, outras recordações, outros lugares da memória e evocam fragmentos do passado que se cristaliza em um imaginário.". Pode-se afirmar então, que através destes lugares privilegiados na memória da população e que ainda existem na paisagem é 
possível resgatar fatos e acontecimentos de destaque para a história da cidade, bem como momentos importantes para os seus habitantes.

A partir desse momento o espaço da cidade deixa de ser homogêneo, sendo fragmentado devidos aos diferentes valores que a população atribuí a paisagem. Nesta perspectiva, a paisagem cedrense passa a ser dimensionada na perspectiva do vivido, onde ela é experimentada e reestruturada pelas práticas cotidianas, "local onde o homem exprime sua relação geográfica com o mundo" (DARDEL, 2011, p, 30). É, portanto, atribuindo ao espaço uma carga simbólica imbuída de significados, que imprimem nas paisagens certos valores, frutos da relação histórica do homem com o espaço.

\section{Considerações Finais}

Apesar das mudanças que ocorreram em Cedro nas últimas décadas, a ferrovia e as formas simbólicas resultantes, continuam a influenciar na construção cotidiana da paisagem, ajudando a preservar a identidade ferroviária e a essência da cidade. independentemente da atividade ferroviária ter sido descontinuada e não estar mais presente fisicamente em Cedro, ela continua ativa no imaginário popular, exprimindo práticas simbólicas e afetivas, gerando nas pessoas que ali vivem um sentimento de pertencimento.

Foi nesse cenário que em 2003, deu-se início as ações para valorizar os exferroviários, e a origem ferroviária de Cedro. A prefeitura municipal adquire os prédios da ferrovia, dando início a uma série de eventos para a valorização da identidade ferroviária. É instituído no dia 25 de outubro o dia municipal do ferroviário, data em que a locomotiva "Baronesa" entrou em atividade (Pereira e Muniz, 2011, p. 61). Além da comemoração do dia do ferroviário, houve a mobilização da população para assistir à chegada das composições, onde os ex-ferroviários esperavam na estação. esses momentos podem ser observados na reportagem do Jornal Diário do Nordeste de 21 de outubro de 2005.

Conforme afirma Pereira e Muniz (2011, p. 62), esses eventos tiveram uma importância regional, mobilizando um grande número de ex-ferroviários para prestigiar as comemorações na cidade. Nesse período, onde se localiza o Giradouro, foi criado o Memorial da Ferroviário RVC/RFFSA, sendo agrupado alguns vagões antigos de momentos distintos do período ferroviário, reunindo aparatos e uma pequena biblioteca, sobre a temática ferroviária. Esses eventos associados a forma simbólica espacial da estação, juntamente com o Giradouro, foram primordiais para a revalorização da essência ferroviária da cidade, dando início a restruturação da identidade local. Para que isso ocorresse, as formas simbólicas foram valorizadas como lugares de memória, tanto individual quanto coletiva, capazes de representar a história da cidade. Nesse sentido, a memória e os valores simbólicos associados a essas formas foram fundamentais na construção do sentimento de identidade. Sobre essas questões Pollak $(1992,204)$ afirma que há uma relação intrínseca entre a memória e o sentimento de identidade, sendo a memória "elemento constituinte do sentimento de identidade, tanto individual quanto coletivo", condição indispensável enquanto o processo de construção de individuo/grupo e da identidade social.

Em Cedro esses processos se intensificaram com a aproximação do centenário da estação ferroviária, no qual a sociedade civil se mobilizou para reconstruir o prédio, e 
que no local fosse criado um museu. Por sua vez as ações de reconstrução e revalorização das formas simbólicas se expandiram para outras estruturas, sendo reconstruído o antigo SENAI e pôr fim a casa do Cel. João Cândido e o seu entorno. Apesar do processo de revalorização dessas formas e, consequentemente, da identidade ferroviária terem resultado na reorganização de algumas formas simbólicas, outras permaneceram ignoradas por parte da administração municipal, como é o caso da Vila Operária, das usinas e até mesmo o Giradouro onde se localizava o memorial ferroviário e foi umas das primeiras formas simbólicas a ser ressignificada.

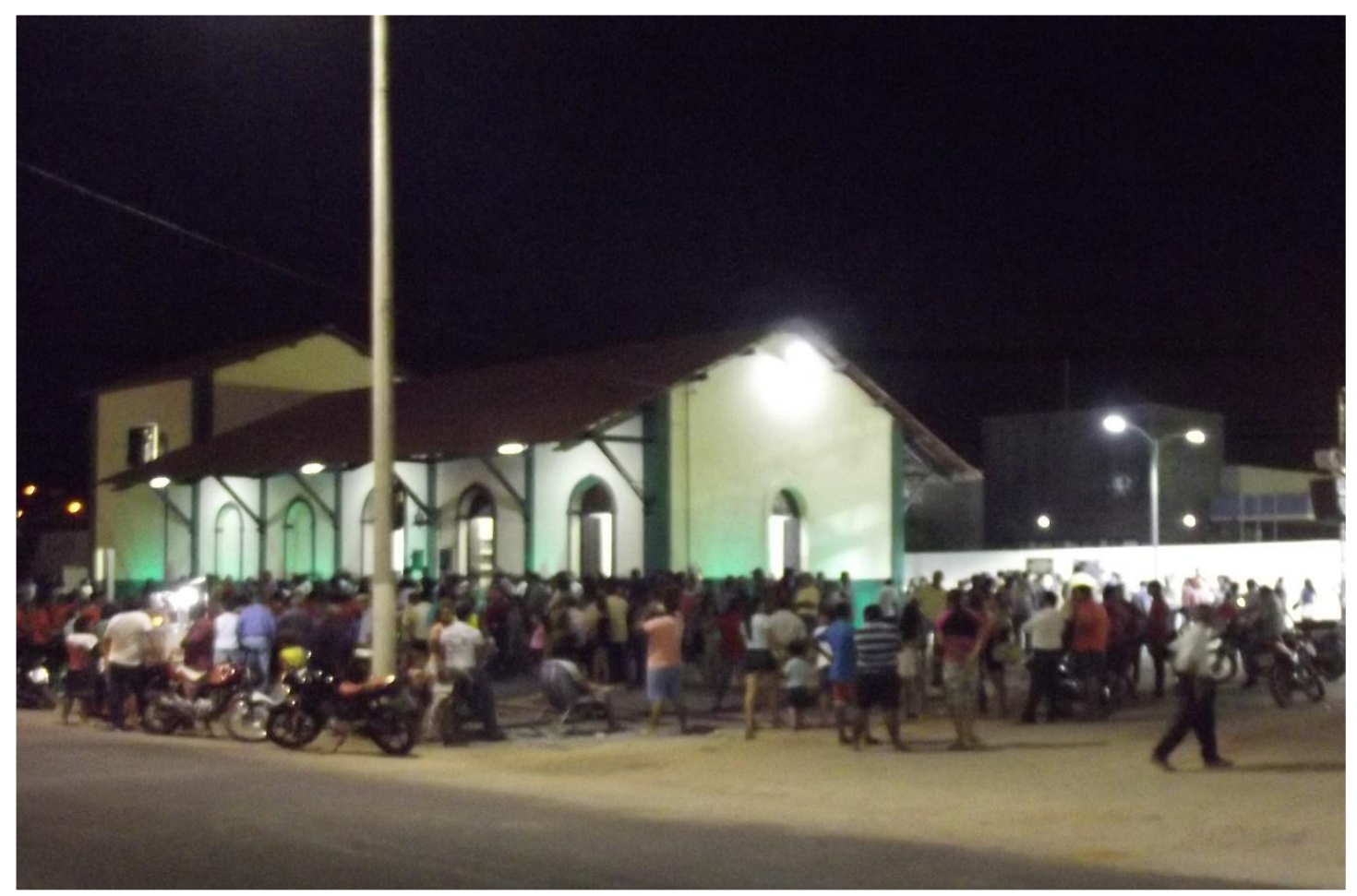

Figura 3: Reinauguração da estação ferroviária e comemoração dos 100 anos da sua construção (15/11/2016). Fonte: Viana, 2016.

Apesar do processo de revalorização dessas formas e, consequentemente, da identidade ferroviária terem resultado na reorganização de algumas formas simbólicas, outras permaneceram ignoradas por parte da administração municipal, como é o caso da Vila Operária, das usinas e até mesmo o Giradouro onde se localizava o memorial ferroviário e foi umas das primeiras formas simbólicas a ser ressignificada. Conclui-se, que a atuação da R. V. C. no desenvolvimento da cidade vai além do patrimônio edificado, é também uma herança cultural que remonta a origem da cidade, revelando a sua história e a formação do seu povo, de modo, que as tradições ligadas ao cotidiano da ferrovia permaneceram vivas na memória da população. Onde seus valores e suas significações ainda estão presentes, e são frequentemente repassados para as gerações que não vivenciaram o período ferroviário. 
Referências

ASSIS, R. J. S. Ferrovias de papel: projetos de domínios territoriais no Ceará (18641880). 2011. 166 f. Dissertação (Mestrado em Geografia) - Centro de Ciências, Universidade Federal do Ceará, Fortaleza, 2011.

BOSI, Ecléa. Memória e sociedade: Lembrança de velhos / Ecléa Bosi. - 3. Ed. - São Paulo: Companhia das Letras, 1994.

O Tempo Vivo da Memória: Ensaios de Psicologia Social. / Ecléa Bosi. São Paulo: Ateliê Editorial, 2003.

BRAUDEL, Fernand. O Espaço e a História no Mediterrâneo. Tradução Marina Appenzeller - 1a ed. São Paulo: Martins Fontes, 1988.

1902 - 1985. Escritos sobre a história / Fernand Braudel; [tradução J. Guinburg e Tereza Cristina Silveira Mota]. - 3. Ed. São Paula: Perspectiva, 2014.

CAMELO FILHO, José Vieira (Zuza). A implantação e consolidação das estradas de ferro no nordeste brasileiro I José Vieira Camelo Filho (Zuza). - Campinas, SP: [s.n.], 2000. Orientador: Ronaldo Marcos dos Santos. Tese (Doutorado) -Universidade Estadual de Campinas. Instituto de Economia.

CÂNDIDO, Tyrone Apollo Pontes. Trem da seca: sertanejos, retirantes e operários (1877 -1880): Tyrone Apollo Pontes Cândido - Fortaleza: Museu do Ceará. Secretaria de Cultura do Estado do Ceará, 2005. 128p.

CAPELO FILHO, Jose. Arquitetura Ferroviária do Ceará: Registro Gráfico e Iconográfico. / José Capelo Filho e Ligia Sarmiento. Coedição com a Secretaria de Cultura do Estado do Ceará - Secult. - Fortaleza UFC, 2010.

CLAVAL, Paul. A geografia cultural / Paul Claval; tradução: Luís Fugazzola Pimenta, Margareth de Castro Afeche Pimenta. - 4 ed. rev. - Florianópolis: Ed. da UFSC, 2014.

CORTEZ, Ana Isabel Ribeiro Parente. Memórias descarriladas: o trem na cidade do Crato / Ana Isabel Ribeiro Parente Cortez; Kênia Sousa Rios (orientadora). 2008.

COSTA, Candido Acrísio. Gente da gente: dados biográficos de famílias de Lavras da Mangabeira (Várzea Alegre e Cedro). Fortaleza - Ceará, 1979.

DARDEL, Eric, $\mathbf{O}$ homem e a terra: natureza da realidade geográfica / Eric Dardel; São Paulo: perspectiva, 2011.

FERREIRA, Benedito Genésio. A estrada de ferro de Baturité: 1870 - 1930; Projeto História do Ceará, politica, industrias e trabalho 1930-1964. Fortaleza, Edições Universidade Federal do Ceará/Stylus Comunicações, 1989. 198 p.

$\mathrm{FICl}$, Ricardo Petrillo. As ferrovias Brasileiras e a Expansão Recente para o CentroOeste. Cadernos Geográficos. Florianópolis, Número 19 - Junho 2010.

IPECE. A QUESTÃO DOS LIMITES MUNICIPAIS DO ESTADO DO CEARÁ - V-1 IPECE, 2012 - Fortaleza - CE.

JUCÁ, Gisafran Nazareno Mota. O Significado da Ferrovia no Cotidiano da Vida Interiorana. In: O Público e o Privado - №2 - Julho/Dezembro - 2003. 
GUIRARDELLO, Nilson. Cidades e Ferrovias. In: TERRITÓRIOS E CIDADES: PROJETOS E REPRESENTAÇÕES, 1870-1970. Organizadores: Cristina de Campos, Eduardo Romero de Oliveira, Maria Lucia Caira Gitahy. São Paulo: Alameda, 2011.

SANTOS, Milton. A Urbanização Brasileira / Milton Santos. - 5a Ed. 2a Reimpressão. (Coleção Milton Santos; 6). - São Paulo: Editora da Universidade de São Paulo, 2009.

SANTOS, Milton; SILVEIRA, Maria Laura. O Brasil: território e sociedade no final do século XXI / Milton Santos, Maria Laura Silveira. - 5a ed. Rio de Janeiro: Record, 2003.

MONASTIRSKY, Leonel Brizolla. FERROVIA: PATRIMÔNIO CULTURAL Estudo sobre a ferrovia brasileira a partir da região dos Campos Gerais (PR) Tese de Doutorado aprovada pelo Programa de Pós-Graduação em Geografia, Centro de Filosofia e Ciências Humanas da Universidade Federal de Santa Catarina. Florianópolis, 2006.

PEREIRA, José Hamilton; MUNIZ, Túlio de Souza. Os descaminhos de ferro do Brasil. José Hamilton Pereira e Túlio de Souza Muniz. Fortaleza; Associação de Estudos e Pesquisas da Subjetividade (AEPS) Expressão Gráfica Editora, 2011.

POLLAK, Michael. Memória e Identidade Social. Estudos Históricos, Rio de Janeiro, vol. 5, n. 10, 1992, p. 200-212.

PONTES, Lana Mary Veloso de. Formação do Território e Evolução PolíticoAdministrativa do Ceará: A Questão dos Limites Municipais / Lana Mary Veloso de Pontes. Fortaleza: IPECE, 2010.

SILVA, Wendell Guedes da. A todo vapor! Formação de trabalhadores na estrada de ferro de Baturité (1877 - 1880) / Wendell Guedes da Silva. - 2013. CD-ROM 120 f:. il. (algumas color); 43/4 pol. Dissertação (mestrado) - Universidade Estadual do Ceará, Centro de Humanidades, Curso de Mestrado Acadêmico em História, Fortaleza, 2013.

SILVEIRA, Márcio Rogério. A importância geoeconômica das estradas de ferro no Brasil /Márcio Rogério Silveira. - Presidente Prudente: [s.n.], 2003. Tese (doutorado). Universidade Estadual Paulista, Faculdade de Ciências e Tecnologia Orientador: Armen Mamigonian.

SPOSITO, Eliseu Savério. Redes e Cidades. /Eliseu Savério Sposito. São Paulo: Editora UNESP, 2008. 